\title{
Supplier Density and At-home Care Use in Japan: \\ Evidence from a Micro-level Survey on Long Term Care Receivers
}

by

Haruko Noguchi and Satoshi Shimizutani*

* This study was originally prepared for the "Final Meeting for ESRI International Collaboration Projects 2004” (February, 2005, Tokyo) sponsored by the Economic and Social Research Institute (ESRI), Cabinet Office, Government of Japan. The paper was also presented at the European Conference on Long-term Care sponsored by the ZEW (October, 2005, Mannheim) and the abstract of the presentation was included in a special issue for the conference (Shimizutani (2006a)). We are grateful to Matteo Lippi Bruni, Yasushi Iwamoto, Olivia Mitchell, Terri Nii, Tadashi Yamada, Peter Zweifel and other participants of the two conferences for their valuable comments. We would also like to express our appreciation for the permission to use the micro-level data collected by the Price Policy Division and ESRI. The views expressed in this paper do not represent those of ESRI or of the Japanese government or any other institution the authors belong to. All errors are our own.

Haruko Noguchi: National Institute of Population and Social Security Research. Address; Hibiya Kokusai Building $6^{\text {th }}$ Floor, Uchisaiwaicho 2-2-3, Chiyoda-ku, Tokyo Japan 100-0011. E-mail:h.noguchi@ipss.go.jp.

Satoshi Shimizutani (Corresponding author): Senior Research Fellow, Institute for International Policy Studies (IIPS). Address; Toranomon 30 Mori Building, 6th Floor, Toranomon 3-2-2, Minato-ku, Tokyo Japan 105-0001; Tel: 03-5404-6651, E-mail:sshimizutani@iips.org. 


\begin{abstract}
$\underline{\text { Abstract }}$
Following the introduction of the long-term care insurance scheme and deregulation of the market for at-home care services, Japan experienced a substantial increase in expenditure on care for the elderly. Using household-level survey data, we empirically examine whether the increase in care expenditure is associated with supplier density springing from the rise in the number of care providers following deregulation. We provide weak evidence that supplier density in the at-home care market is positively correlated with probability to use care or expenditure on care. Moreover, we find no link between the share of for-profit providers and the demand for at-home care services.
\end{abstract}

Key words: supplier density; at-home care; long-term care insurance JEL classification: I11 


\section{Introduction}

Following the introduction of the public long-term care insurance scheme in FY2000, a rapid increase in elderly care utilization through this new scheme has been observed in Japan. According to the official data compiled by the Ministry of Health, Labour and Welfare, the total costs of long-term care covered by the insurance began to mount quickly since FY2001. In FY2006, expenses on care use totaled 6.43 trillion yen, an 82.7 percent increase from the 3.52 trillion yen in FY2000. This remarkable expansion was brought about mainly by at-home care rather than by institutional care.

The rapid expansions of long-term care use can be partly explained by the realization of potential demand for elderly care, which was suppressed before 2000, and thus is a temporal phenomenon. Based on the unprecedented speed of population aging in Japan, however, this steadily increasing trend of long-term care use is expected to continue and, if the current system is maintained, is likely to create an enormous fiscal burden in the future. ${ }^{1}$ This prospect of colossal care expenses has triggered a policy debate on how to design a sustainable long-term care insurance scheme. Most of the reforms which have either come into effect or which are still being debated focus on the care-user side to control excess demand for long-term care as a means to keep increases in the total cost of care for the elderly in check.

However, we suspect that the rapid demand expansion may also have been driven by suppliers, rather than demanders - a possibility which has hardly been explored. What we would like to argue here is that this increase in the number of care providers following the entry

\footnotetext{
${ }^{1}$ The Ministry of Health, Labour and Welfare (2003) has warned that the amount of expenditure on elderly care will probably rise to some 20 trillion yen in 2025 (the year in which the share of the elderly in the overall population is expected to peak), which would be equivalent to 3.5 percent of national income and 11.4 percent of social security expenditure.
} 
deregulation in 2000 has played a role in stimulating care demand and thus contributed to the rapid rise in costs. To our best knowledge, this is the first study to use micro-level survey data to examine the relationship between supplier density and at-home care use and to do so using a modified two-part model (three-part model) to distinguish between supply and demand side factors. Our dataset contains rich information on household demographics and health status, with which household care demand is closely related. Moreover, in contrast with previous studies, the present paper also focuses on the at-home care markets and pays attention to the different behavioral characteristics of nonprofit and for-profit providers.

Under the public insurance system, care suppliers are reimbursed on a fee-for-service basis and they face an incentive to create care needs. Moreover, care managers may be tempted to increase the demand for services supplied by the care provider which employs him/her. In addition, For-profit providers have been allowed to operate in the at-home care market since 2000 and the opportunistic behavior of this new type of providers, which is often used to justify a ban on the entrance of for-profits, may create new care needs. In other words, there is considerable room for care suppliers to induce demand for unnecessary care to raise profits, and the incentive to do so has become stronger as the market for care provision has become more crowded (Yuda (2005)). This type of supplier moral hazard has been widely discussed in the health economics literature under the heading of supplier (physician) induced demand (henceforth, SID).

However, whether such SID exists, and, if it does its magnitude, remains a matter of debate. One explanation for the possible existence of SID is information asymmetry. In the health care field, information asymmetry between suppliers and demanders arises because decisions often require a high level of expertise; therefore, consumers typically are unlikely to decline any services proposed by suppliers. Consequently, when the number of suppliers 
increases and the market becomes more competitive, suppliers take advantage of such information asymmetry and stimulate demand for unnecessary services to compensate for income losses.

The SID hypothesis has been examined in a large number of studies, beginning with the seminal analyses by Evans (1974) and Fuchs (1978). ${ }^{2}$ However, the empirical evidence both on the existence and potential magnitude of SID has remained rather inconclusive. While there are a considerable number of studies that support the SID hypothesis, most have failed to distinguish between the supplier-induced demand and the possibility that increased in demand reflect patient preferences. While a greater number of suppliers invites the possibility of SID, it at the same time affects patient preferences through lower access costs. ${ }^{3}$ Moreover, suppliers’ location choice (reverse causality) or excess demand for care might be responsible for a positive relationship between the supply density and the expenditure. One effective way to do so is to employ a two-part model, which divides total medical costs into two components: the probability of receiving medical services, and medical costs per patient (see, e.g., Escarce (1992), Rossiter and Wilensky (1984)). Using such an approach, Escarce (1992), for example, found that physician density affects the share of patients who go to receive medical services, but it does not affect the medical expenditure for the patients.

As far as we know, there are only two previous studies that have examined SID in Japan’s elderly care markets, Yamauchi (2004) and Yuda (2005). Yuda (2005) applied a two-part model to prefecture-level data and suggested that care provider density affects patient care costs with regard to several types of care services, but does not alter the care expense per care user. These

\footnotetext{
2 A summary of the substantial literature on this topic is provided by McGuire (2000).

3 A famous study casting doubt on studies purporting to find evidence of SID is the one by Dranove and Wehner (1994), who applied econometric methods used in earlier studies and found a statistically positive relationship between the number of physicians and childbirths - an area where SID is highly unlikely.
} 
studies utilized prefecture-level data and examined the relationship between elderly care expenses in each prefecture and care provider density, without controlling for households demographics.

The reminder of this study is organized as follows. Section 2 describes Japan's public long-term care insurance and the at-home care industry. Section 3 explains the dataset used in this study. Section 4 turns to the empirical evaluation based on the two-part model, while Section 5 concludes.

\section{The At-home Elderly Care Market in Japan}

The elderly care market in Japan fundamentally changed after the introduction of the public long-term care insurance program in FY2000. ${ }^{4}$ Before FY2000, under the “distribution system,” only lower-income households were eligible to receive elderly care provided by the local government, as a social welfare measure. Such households could not choose between providers nor could they choose the content of services, which they received from local government-designated nonprofit providers and the number of providers was heavily controlled. These arrangements changed with the introduction of the public long-term care insurance scheme in FY2000. Under this scheme, which operates under a pay-as-you-go program, financed by a combination of earmarked premiums levied on insured persons and general tax revenue (Mitchell, et al. (2006)), all insured persons are entitled to use care provided in the home (at-home care) or in facilities (institutional care) once they are certified by local governments to be in need of long-term care. Care managers are in charge of determining the care needs of each eligible person.

\footnotetext{
${ }^{4}$ More detailed information on Japan's public long-term care insurance can be found in Shimizutani and Noguchi (2004), Mitchell, et. al. (2006) and Shimizutani (2006b).
} 
The insured are entitled to use elderly care from any provider at a 10-percent copayment of officially fixed prices specific to each type of care. ${ }^{5}$

Under the public long-term care program, prices are regulated for each type of service by the central government (the types of services are also regulated), and are applicable to all care providers in Japan. Particular services are assigned a certain number of standard "units” by the Ministry of Health, Labour and Welfare, and each unit is then valued by region to take into account regional wage differentials. ${ }^{6}$ In other words, care providers are not able to set their prices freely since uniform nationwide rates are applicable for all covered LTC services, which are also standardized. While the intention of this system is for at-home care providers to compete on quality rather than on price, care providers face an incentive to create care needs.

At the same time that the long-term insurance scheme was introduced in 2000, entry regulations were liberalized and became more market-oriented. Government deregulation of the at-home care sector for the elderly for the first time allowed for-profit providers to compete directly with nonprofit operators (Shimizutani and Noguchi (2004), Mitchell, et al. (2006)). The at-home care market had been monopolized by nonprofits, although for-profits are still not allowed to operate in the institutional care market. The deregulation aimed to overcome the bottleneck in care supply and a number of new providers have since entered the market.

These characteristics of Japan’s public long-term care insurance leave substantial room for the creation of care demand. In this context, the following three aspects play a particularly important role. First, the fee-for-service scheme offers providers an incentive to generate unnecessary elderly care use since an increase in the supply of care is not associated with a decrease in prices. Second, care expenditures are paid for by the public

\footnotetext{
${ }^{5}$ However, beyond a certain threshold that depends on the care level, the care receiver must pay 100 percent of any additional costs up to a stop-loss threshold called the "high-cost long-term care service limit."

${ }^{6}$ One unit is worth $¥ 10-10.72$.
} 
insurance scheme and the out-of-pocket burden on care receivers is limited, meaning that the potential demand for long-term care is vast and there is little incentive for providers to discourage such demand. ${ }^{7}$ Third, care managers, who are supposed to play a role in the proper allocation of care services, may be tempted to increase the demand for services supplied by the care provider which employs him/her.

\section{Description of the Data}

The data set used in this study is the micro-level data from the "Survey on Long-term Care Users.”8 This survey was performed three times, in 2001, 2002 and 2003. The first survey was conducted from November to December, 2001, by the Price Policy Division of the Cabinet Office (Cabinet Office (2002)). The subjects of this survey were drawn from among the respondents of a survey carried out by a private research firm. The households were randomly chosen based on Japan's household registration system, and the distribution resembles the census data. Each household in the sample has only one care receiver who needs care in daily life, and both certified care receivers (i.e., care receivers certified by the local government to be eligible for services through the public insurance scheme) and uncertified care receivers are included. Households with care receivers living separately from family members in an institution as well as households with two or more care receivers are excluded from the sample. ${ }^{9}$ The research company mailed the questionnaire to 1,300 households and received responses from 1,005 households (for a response rate of 77.1 percent).

\footnotetext{
${ }^{7}$ Delattre and Dormont (2003) make this point with regard to France.

${ }^{8}$ See Noguchi and Shimizutani (2005), which used the same dataset, for more detailed information.

${ }^{9}$ The screening results show that households with one care receiver account for 71.1 percent of the total, those with two care receivers account for 26.9 percent, and the remainder are households with more than two care receivers.
} 
The second survey was conducted by the Economic and Social Research Institute (ESRI) by outsourcing to the same research firm in October and November 2002. The second survey is very similar to the first one and on the same households as in the 2001 survey. Of the 1,005 households in the first survey, responses were obtained from 822 (a response rate of 81.8 percent). Among those 822 households that responded, there were 617 in which the care receiver still lived at home with family members and received at-home care. ${ }^{10}$ In addition, new households with one care receiver were selected, as a result of which 457 new households were added to the sample. Thus, the sample size for 2002 is 1,074 households. The third survey was also implemented by ESRI, in December 2003. The data were obtained following the same methodology as in 2002. Of the households surveyed both in 2001 and 2002, the questionnaire was mailed to 544, and responses were obtained from 381 households with a care receiver at home. Of those first surveyed in 2002, the questionnaire was sent to 432 households and 251 households responded. In addition, the survey was mailed to 423 households which were newly chosen in 2003, and responses were received from 349. Thus, the sample size for 2003 is 981 households.

The respondents to the survey were the main caregivers in the household. The questionnaire covers a variety of items to establish patterns of care use over a period of several years, including the health condition of caregivers and receivers and household demographics. From these surveys, we use the 2002 and 2003 results due to a lack of data on the number of care providers at the prefectural level in 2001. Moreover, we need lagged income and assets data in order to avoid possible endogeneity in the estimation. We confined the sample to households which were surveyed in the previous year and for which information for the variables used in the estimation are available. As a result, the sample size is 520 for 2002 and 545 for 2003.

\footnotetext{
${ }^{10}$ Of the 205 elderly care receivers who no longer lived at home with family members, 75 entered an unspecified type of institution, 68 died, and 29 were hospitalized.
} 
Table 1 reports the summary statistics. The share of households in which there was a care receiver who was certified to use care through the long-term care insurance scheme exceeded 70 percent and that of households in which there was a care receiver who received at-home care is about 60 percent in both surveys. The amount of out-of-pocket expenditures on care is 12,000 yen to 14,000 yen per month. Turning to the characteristics of care receivers, more than 70 percent were female and the average age was above 80 . Persons with care levels 1 and 2 accounted for the largest shares, because those with higher care levels are more likely to be institutionalized. The diseases responsible for the initial care are mainly cardiovascular diseases, such as hypertension and arteriosclerosis, as well as Alzheimer's disease or Parkinson's disease, kidney related diseases (e.g., chronic renal failure), and respiratory disease (e.g., asthma and chronic bronchitis). The average number of hours of care needed was approximately 5.5 to 6 hours per day. On average, patients in the sample used outpatient medical care more than three times per month and their out-of-pocket medical expenditure was between 4,000 and 5,000 yen. As regards households' economic status, the mean annual household income in our sample is more than 7 million yen and the mean assets are over 40 million yen, half of which are owned by care receivers. Moreover, in around 80 percent of households, the household budget is shared between the elderly member and other household members. The share of those with their own house is around 90 percent.

Finally, we look at the measure of supplier density. Unfortunately, information on the turnover or capacity of at-home care providers is not available. Due to these data limitations, we use as our density measure the number of at-home care establishments in each prefecture. The information is available as of the end of September of each year and is obtained from the "Survey on Care Institutions and Establishments (Kaigo Service Shisetsu Jigyosho Chosa)” compiled annually by the Ministry of Health, Labour and Welfare. This is a census survey that collects 
information from all care providers from all areas of Japan and hence allows us to calculate the number of at-home care establishments in each prefecture. ${ }^{11}$ As stated above, the households in our survey are those that have a care receiver, and households with a care receiver receiving institutional care are excluded. The number of care establishments is defined as the sum of establishments that provide home-visit services, home-visit bathing, home-visit nursing or day care. In order to measure care provider density, we take the number of certified elderly care receivers in a particular prefecture as the denominator. ${ }^{12}$ Moreover, we use the density measure in the previous years for the regressions to mitigate reverse causality from long-term care use to the number of providers. As shown in Table 1, the average number of care providing establishments per person was 0.010 in 2002 and 0.009 in 2003. In other words, the average number of customers per establishments for all prefectures is about 100. The share of for-profits out of all establishments was less than a quarter in 2002 and increased to above a quarter in 2003.

\section{Specification and Estimation}

This section provides our specification and empirical results. We employ a three-part model to distinguish between supply and demand side factors. Concretely, we examine separately the determinants of the probability to be eligible for care use through the public

\footnotetext{
${ }^{11}$ Ideally, we would use the density measure at the city-/town-/village-level, but here we use prefecture-level data for two reasons. The first is that there are many cases in which households use care services from providers outside their own city/town/village. This means that the number of providers in such local communities would be underestimated. The second reason is that, so far, we have been unable to obtain data on the number of establishments by municipality. While WAM-NET (the "Welfare And Medical Service NETwork system" operated by Fukushi Iryo Kiko) now provides such data, data for the years covered in our analysis are not available.

${ }^{12}$ Yamauchi (2004) takes the number of those who actually receive care services of any type as the denominator. But, as highlighted by Yuda (2005), there is a discrepancy between those who are eligible and those who actually receive any services, that is, there are some who are eligible but choose not to use any care services through the insurance. Here, we follow Yuda (2005) and use the number eligible persons rather the number of actual care receivers.
} 
insurance program (first part), the probability of care use initiated by users (second part) and per unit care expenditure determined by suppliers (third part) and evaluate the effect of provider density on either of these factors. In accordance with the sample design in our survey, we define the share of those who actually use at-home care as those who receive at-home care services of any type, including home-visit services, home-visit bathing, home-visit nursing, home-visit rehabilitation, and day care. Care expenditure is defined as the monthly expenditure on these services. $^{13}$

The specifications we employ are as follows:

(1) First part: being certified $Y_{1 i}^{*}=\alpha_{0}+\alpha_{1} X_{1 i}+\alpha_{2}$ Density $_{j}+\varepsilon_{i}$

(2) Second part: receiving care for those who are certified $Y_{2 i}^{*}=\beta_{0}+\beta_{1} X_{2 i}+\beta_{2}$ Density $_{j}+\varepsilon_{i}$

(3) Third part: monthly expenditure on care per person for those who are certified and choose to use care $\ln (\operatorname{Exp})_{i}=\gamma_{0}+\gamma_{1} X_{2 i}+\gamma_{2}$ Density $_{j}+\varepsilon_{i}$

where $i$ denotes a household and $j$ does a prefecture in which household $i$ lived. The dependent variables in (1) and (2) are the probability of being certified or receiving at-home care. We cannot observe the propensity $Y_{1 i}^{*}$ or $Y_{2 i}^{*}$ directly, but we have information on whether an individual was actually certified and whether the person actually received at-home care of any

\footnotetext{
13 Unfortunately, there is no information on expenditure on each service in the survey and we are not able to perform those regressions separately for each type of care.
} 
type. Thus, the dependent variable is a binary variable that takes 1 if an individual was certified in (1) and if the person received at-home care of any type in (2), and 0 otherwise. The independent variables are common in (1) and (2) including household characteristics and the density measure described in Table 1, as well as dummy variables for ten regional groups to capture indigenous regional characteristics, with a lack of care levels in (1).

We perform a probit estimation using cross-sectional data for 2002 and 2003 separately to explore any changes in the effect of care provider density on the choice of being certified and the use of care services between the two years. The dependent variable in (3) is the logarithm of expenditure on care per month. The independent variables in (3) are identical to those in (2) except that the share of for-profits in the total number of providers is used as an additional variable. We include this variable since there have been concerns that for-profits resort to opportunistic behavior to increase profits.

Table2 shows the regression results for equations (1) and (2), respectively. Robust standard errors are used for all regressions. The results in Table 2 indicate that age of care receiver, suffering from cardiovascular diseases or a respiratory disease, and the number of hours of care needed have a positive and significant effect on the choice of being certified. Moreover, the table shows care receiver characteristics such as the care level, suffering from a respiratory disease such as asthma or chronic bronchitis, and the number of hours of care needed per day have a positive and significant effect on the probability of receiving at-home care, both in the 2002 and the 2003 sample. As regards households' economic status, households whose budget was shared between care receivers and other household members were less likely to use at-home care in both years. One possible interpretation of the negative correlation between the elderly person's share in household assets and the use of at-home care is that it shows the presence of a strategic bequest motive on the part of caregivers. 
Turning to the coefficients on the density measure, which interests us most, the results, as shown in Table 2, are not statistically significant, suggesting that a higher care provider density is not associated with a higher probability of being certified in both years and care receipt in 2002 . However, the coefficient is positive and significant for the choice of care use in 2003. In other words, user preferences do not much affect the use of long-term care in 2002 but in 2003. We will discuss this point later.

The results in Table 3 indicate that, in 2002, care receiver characteristics such as care levels and hours of care needed per day have a significant positive effect on monthly expenditure on care per person but this is not the case for 2003. Moreover, Table 3 shows that monthly long-term care expenditure is positively correlated with the number of outpatient days per month and out-of-pocket expenditure in 2003. The results related to households' economic status vary for the two years; for 2002, we obtain a positive and significant coefficient on household income and assets but not in 2003. Instead, we see a larger share of care receiver’s assets in total household assets is negatively correlated with monthly long-term care expenditure in 2003, not in 2002.

Table 3 also shows that the coefficient on the density measure is not significant in 2002 but significant in 2003. The results here indicate little evidence that a higher number of providers per person is associated with higher monthly expenditure on care in 2002 but some evidence in 2003. In addition, of greatest interests here is that the coefficient on the share of for-profits is insignificant or significantly negative in both years, implying that a higher share of for-profits is not associated with a greater use of elderly care. In other words, we find no evidence that for-profits resort to opportunistic behavior to artificially induce care demand.

So far, we focused on our discussion based on the estimation results separately for 2002 and 2003. Before turning to the discussion on the interpretation of the correlation between 
supplier density and at-home care use, we perform additional regressions using the individual-level panel data. As explained in Section 3, the survey used in this study was conducted in 2001, 2002 and 2003 and 381 individuals were in the sample for three times. We use the first difference estimation to remove the unobserved heterogeneity of individuals and examine the effect of change in supplier density on change in care use. ${ }^{14}$ The dependent variable for (1) takes 1 if an individual in the sample was not certified in 2002 but certified in 2003, 0 if the status of being certified was not changed between 2002 and 2003 and minus 1 if an individual was certified in 2002 but not in 2003. Similarly, the dependent variable for (2) takes 1 if an individual in the sample did not use any care services in 2002 but actually used in 2003, 0 if the status of care use was not changed between 2002 and 2003 and minus 1 if an individual used care services in 2002 but not in 2003. Moreover, the dependent variable for (3) is a change in logarithm of monthly expenditure on care between 2002 and 2003. In the first difference estimation, we take a difference for all the independent variables employed in Table 2 or Table 3. We dropped sex and prefecture since they are constant over years and age since the difference is common for all individuals in the sample and dummy variables for disease that caused care needs since it was asked only once in 2001. We confined the sample to households for which information for the variables used in the estimation are available and the sample size reduced to 300.

Table 4 reports the results. We employ an ordered probit estimation for (1) and (2) and OLS estimation for (3). First, the regression result for (1) shows that most of the coefficients are not statistically significant including the change in the density measure. Second, the results for (2) reveal that the coefficients on the change in care level and on the change in monthly

\footnotetext{
${ }^{14}$ We remind that the information on supplier density at prefecture level is not available in 2001 and we are able to examine the changes between 2002 and 2003.
} 
out-of-pocket medical expenditure are positive and significant, showing that higher care level and medical expenditure are naturally associated with a higher probability to use long-term care. Again, we see that the coefficient on the change in the density measure is not statistically significant. Third, the result for (3) shows positive and significant coefficients on the change in care level and monthly medical expenditure, which are same as the result for (2). In addition, the change in expenditure on care is positively associated with the change in household income and negatively correlated with the changes in houses of care needed and in the number of monthly outpatient days. We observe the coefficients on the change in the density measure and on the share of for-profits are not significant. ${ }^{15}$

Table 2 and Table 3 show that the density measure is positively associated with a higher probability of being certified and higher monthly expenditure on care in 2003 but this is not the case for 2002. However, once we remove unobserved heterogeneity of individuals, we do not observe the positive and significant relationship between the density measure and probability of being certified or between the density measure and monthly expenditure on care. Moreover, in any cases, we do not see any significant effect of the share of for-profit suppliers on probability of being certified or monthly expenditure on care.

In sum, we provide weak evidence that supplier density in the at-home care market is positively correlated with probability to use care or expenditure on care. Moreover, we find no link between the share of for-profit providers and the demand for at-home care services. In the SID literature, it is well known that there are some possible interpretations of the positive relationship between the density and expenditure: SID, location choice (reverse causality), improvement in accessibility to supplier, or excess demand (Zweifel and Breyer (1997)). Since

\footnotetext{
${ }^{15}$ Those results are unchanged even if sex, age and disease that caused care needs are included as independent variables.
} 
the sample size in our data set is not large, we do not deny the possibility that the coefficients reported in the tables are imprecisely estimated and those factors may contribute to the rapid increase in long-term care use after FY 2001. However, the weak evidence on the relationship between the density measure and probability of being certified or between the density measure and monthly expenditure on care implies that the recent expansion of long-term care use was less likely to be caused by those factors.

\section{Conclusion}

Following the introduction of the long-term care insurance scheme and deregulation of the market for at-home care services in FY2000, Japan experienced a substantial increase in expenditure on care for the elderly. Taking advantage of rich and original survey data and using a three-part model, this study examined whether the increase in care expenditure is the result of supplier-induced demand in the wake of the rise in the number of care providers following deregulation. We provide at most weak evidence that supplier density in the at-home care market is positively correlated with probability to use care or care expenditure. Moreover, we also find no link between the share of for-profit providers and the demand for at-home care services.

These results indicate that although both the number of care providers and care costs have risen simultaneously, this does not mean that the latter has been caused by the former. Our finding contrasts with the result obtained by Noguchi, Shimizutani and Masuda (2008), who found clear evidence of supplier-induced demand in high-tech heart attack treatment in Japan. The literature on SID suggests that it is information asymmetry between suppliers and demanders that allows suppliers to create demand for their services. In this context, a likely reason why SID is less likely to be observed in Japan's long-term care market is that there is little 
information asymmetry, because the services provided by suppliers - such as home-visit services, home-visit bathing, etc. - are easy to understand, making it difficult for suppliers to create demand at their will.

While we provide micro-level evidence on the relationship between supplier density and at-home care use in Japan for the first time, further research should examine and quantitatively compare the supply and demand factors in later years so as to identify what accounts for the rapid increase in elderly care use, which holds very important policy implications for both academics and policymakers. Those studies will be empowered by a large data set with rich information on both household demographics and suppliers (i.e., location of providers and the distance to each individual in the sample). 


\section{References}

Cabinet Office (2002) Kaigo service shijo no isso no koritsuka no tame ni [Report on the Long-term Care Market] (in Japanese). Government of Japan.

Delattre, Eric and Brigitte Dormont (2003). "Fixed Fees and Physician-induced Demand: A Panel Data Study on French Physicians,” Health Economics, vol.12, no.9, pp. 741-754.

Dranove, David and Paul Wehner (1994). "Physician-Induced Demand for Childbirths”, Journal of Health Economics vol.13, no.1, pp.61-73.

Escarce, Jose (1992). “Explaining the Association Between Surgeon Supply and Utilization,” Inquiry vol.29, pp.403-415.

Evans, Robert. (1974). “Supplier-Induced Demand: Some Empirical Evidence and Implications,” in Mark Perlman, ed., The Economics of Health and Medical Care; Macmillan, London.

Fuchs, Victor (1978). “The Supply of Surgeons and the Demand for Operations,” Journal of Human Resources vol.13, pp.35-56.

McGuire, Thomas (2000). "Physician Agency,” in A. J. Culyer and J. P. Newhouse, eds., Handbook of Health Economics, volume 1A, pp.461-536. North-Holland.

Ministry of Health, Labor and Welfare (2003). 2015 nen no koreisha kaigo: koreisha no songen o sasaeru care no kakuritsu ni mukete [Long-term Care in 2015: Toward the Establishment of Care that Respects the Dignity of the Elderly] (in Japanese).

Mitchell, Olivia S., Piggott, John and Shimizutani, Satoshi (2006). “Aged-Care Support in Japan: Perspectives and Challenges,” Benefits Quarterly, $1^{\text {st }}$ Quarter, pp.7-18. 
Noguchi, Haruko and Satoshi Shimizutani (2005). “Nonprofit and For-profit Providers in Japan’s At-home Care Industry: Evidence on Quality of Service and Household Choice,” Economics Bulletin vol.9, pp.1-13.

Noguchi, Haruko, Satoshi Shimizutani and Yuichiro Masuda (2008). "Regional Variations in Medical Expenditure and Hospitalization Days for Heart Attack Patients in Japan: Evidence from the Tokai Acute Myocardial Study (TAMIS),” International Journal of Health Care Finance and Economics, vol.8, no.2, 2008, pp.123-144.

Rossiter, Louis and Gail Wilensky (1984). "Identification of Physician-Induced Demand,” Journal of Human Recourses vol.19, no.2, pp.231-244.

Shimizutani, Satoshi (2006a). “The Expansion in Long-Term Care Use in Japan: A Case of Supplier-Induced Demand?” Swiss Journal of Economics and Statistics, Special Issue 2006, pp.91-95.

Shimizutani, Satoshi (2006b). “Japan’s Long-term Care Insurance Program: An Overview,” Swiss Journal of Economics and Statistics, Special Issue 2006, pp.23-28.

Shimizutani, Satoshi and Haruko Noguchi (2004). Kaigo hoiku service shijo no keizai bunseki --- micro data ni yoru jittai kaimei to seisaku teigen [An Economic Analysis of Care for Children and the Elderly in Japan: A Micro-level Investigation and Consideration of Policy Implications] (in Japanese), Toyo-Keizai Shimpo Sha, Tokyo.

Yuda, Michio (2005). “Kaigo jigyosha mitsudo ga kaigo service ni ataeru eikyo” [The Effect of Provider Density on Long-term Care], Kikan Shakai Hosho kenkyu [Quarterly of Social Security Research], vol.40, no.4, pp.373-386 (in Japanese). Yamauchi, Yasuhiro (2004). “Homon kaigo hi to jigyosha mitsudo” [Home Visit Care Expenses and Provider Density] Iryo to Shakai [Journal of Health Care and Society], vol.14, no.2, pp.103-118 (in Japanese). 
Zweifel, Peter and Friedrich Breyer (1997). “The physician as a supplier of medical services”, Health Economics, pp.201-226, Oxford University Press. 
Table 1: Basic statistics

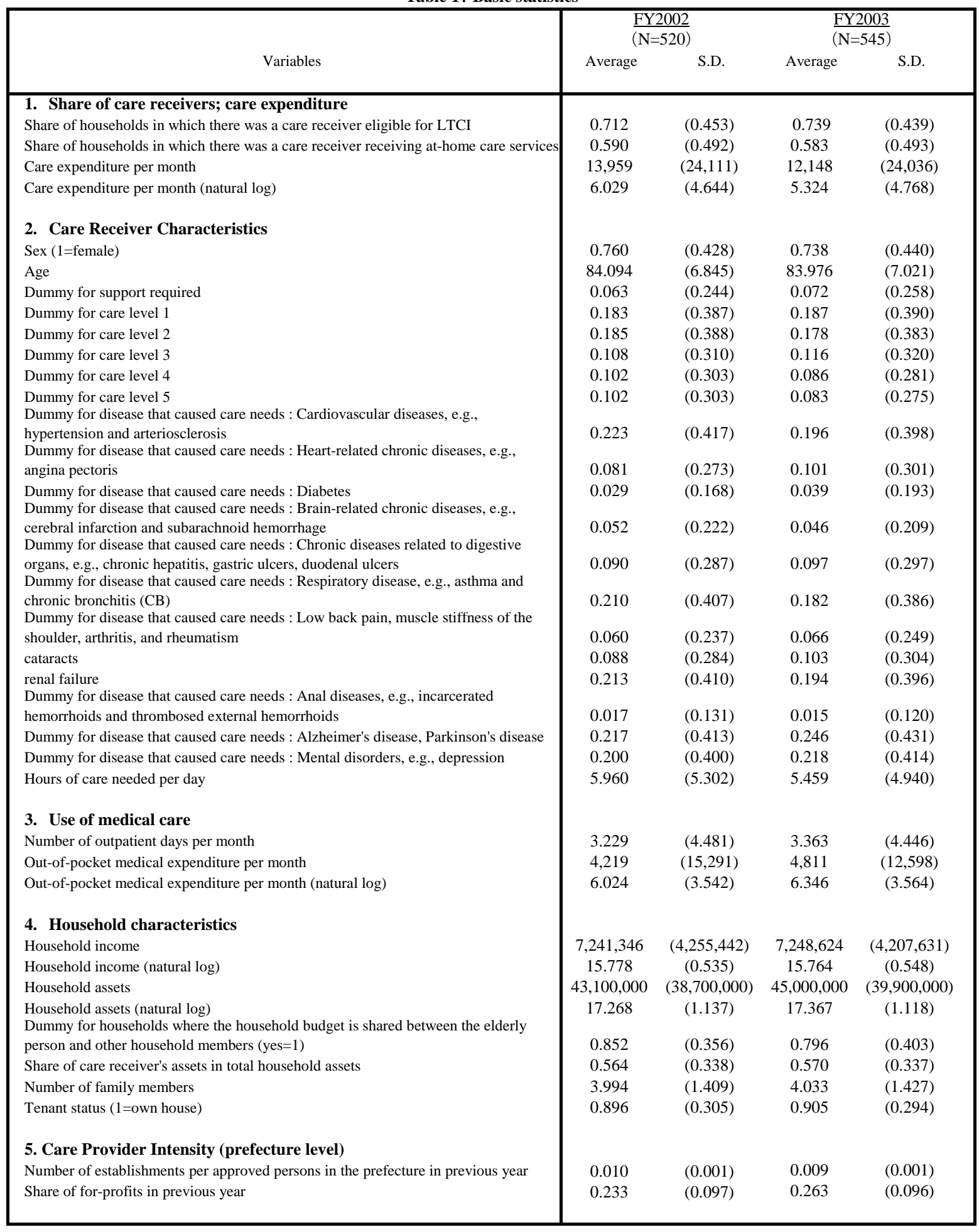


Table 2: Determinants of receiving at-home care services (probit estimation)

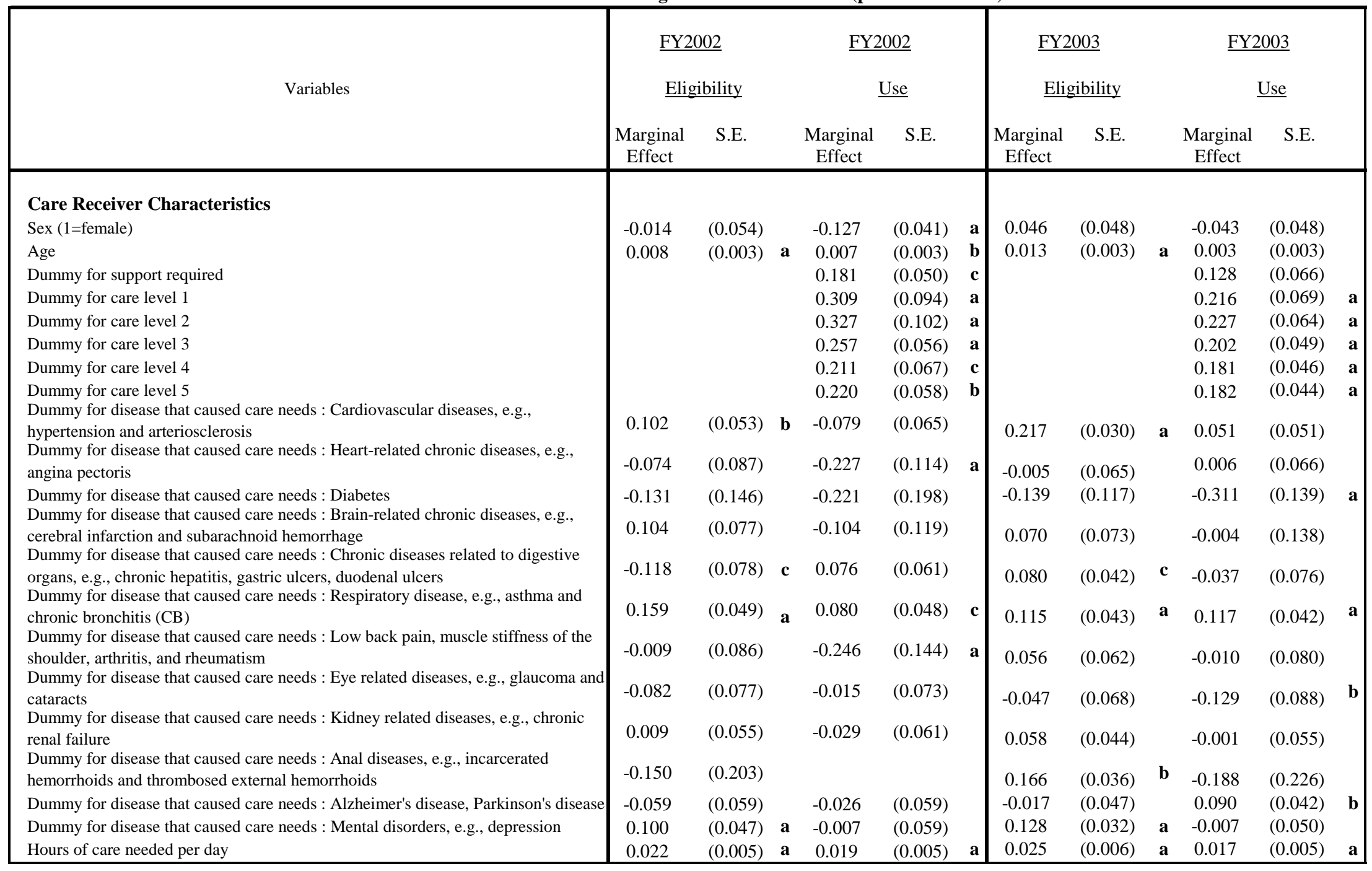


Table 2 (continued)

\begin{tabular}{|c|c|c|c|c|c|c|c|c|c|c|c|c|}
\hline \multirow[t]{2}{*}{ Variables } & \multicolumn{2}{|c|}{$\begin{array}{l}\text { FY2002 } \\
\text { Eligibility }\end{array}$} & \multicolumn{3}{|c|}{$\begin{array}{r}\text { FY2002 } \\
\underline{\text { Use }}\end{array}$} & & \multicolumn{2}{|c|}{$\begin{array}{l}\underline{\text { FY2003 }} \\
\text { Eligibility }\end{array}$} & \multicolumn{4}{|c|}{$\begin{array}{r}\underline{\text { FY2003 }} \\
\underline{\text { Use }}\end{array}$} \\
\hline & $\begin{array}{c}\text { Marginal } \\
\text { Effect }\end{array}$ & S.E. & & $\begin{array}{c}\text { Marginal } \\
\text { Effect }\end{array}$ & S.E. & & $\begin{array}{c}\text { Marginal } \\
\text { Effect }\end{array}$ & S.E. & & $\begin{array}{c}\text { Marginal } \\
\text { Effect }\end{array}$ & S.E. & \\
\hline \multicolumn{13}{|l|}{ Use of medical care } \\
\hline Number of outpatient days per month & -0.009 & $(0.004)$ & $\mathbf{a}$ & 0.007 & $(0.005)$ & & -0.007 & $(0.003)$ & b & -0.004 & $(0.005)$ & \\
\hline Out-of-pocket medical expenditure per month (natural log) & 0.001 & $(0.006)$ & & 0.014 & $(0.006)$ & $\mathbf{a}$ & -0.011 & $(0.005)$ & $\mathbf{a}$ & 0.004 & $(0.005)$ & \\
\hline \multicolumn{13}{|l|}{ Household characteristics } \\
\hline Household income (natural log) & -0.002 & $(0.043)$ & & 0.060 & $(0.043)$ & & -0.019 & $(0.039)$ & & -0.066 & $(0.045)$ & c \\
\hline Household assets (natural log) & -0.0002 & $(0.021)$ & & -0.020 & $(0.021)$ & & 0.015 & $(0.019)$ & & 0.014 & $(0.020)$ & \\
\hline $\begin{array}{l}\text { Dummy for households where the household budget is shared between the elderly } \\
\text { person and other household members (yes=1) }\end{array}$ & 0.010 & $(0.056)$ & & -0.096 & $(0.049)$ & c & -0.162 & $(0.033)$ & a & -0.105 & $(0.039)$ & a \\
\hline Share of care receiver's assets in total household assets & -0.020 & $(0.063)$ & & -0.086 & $(0.061)$ & & -0.067 & $(0.057)$ & & -0.117 & $(0.061)$ & b \\
\hline Number of family members & 0.019 & $(0.015)$ & & 0.001 & $(0.016)$ & & -0.005 & $(0.013)$ & & 0.029 & $(0.015)$ & b \\
\hline Tenant status ( $1=$ own house $)$ & 0.147 & $(0.078)$ & $\mathbf{a}$ & -0.035 & $(0.069)$ & & 0.128 & $(0.078)$ & b & -0.052 & $(0.058)$ & \\
\hline \multicolumn{13}{|l|}{ Care Provider Intensity (prefecture level) } \\
\hline Number of establishments per approved persons in the prefecture & -23.446 & (16.799) & & -10.267 & $(16.605)$ & & -4.557 & $(18.254)$ & & 36.587 & $(21.650)$ & b \\
\hline Number of observations & \multicolumn{2}{|c|}{517} & \multicolumn{3}{|c|}{361} & & \multicolumn{2}{|c|}{545} & & \multicolumn{3}{|c|}{403} \\
\hline Log-likelihood & \multicolumn{2}{|c|}{-265.171} & \multicolumn{3}{|c|}{-155.528} & & \multicolumn{2}{|c|}{-231.762} & & \multicolumn{3}{|c|}{-171.475} \\
\hline Pseudo R-squared & \multicolumn{2}{|c|}{0.148} & \multicolumn{3}{|c|}{0.186} & & \multicolumn{2}{|c|}{0.259} & & \multicolumn{2}{|c|}{0.194} & \\
\hline
\end{tabular}

(Notes) All regressions include regional dummies, which were constructed by grouping prefectures into 10 groups.

Robust standard errors are used. a、 b、 c refer to a significance level of $5 \%, 10 \%$ and $15 \%$, respectively. 
Table 3: Determinants of care expenditure (OLS estimation)

\begin{tabular}{|c|c|c|c|c|c|c|c|c|c|c|c|c|}
\hline \multirow[b]{2}{*}{ Variables } & \multicolumn{2}{|c|}{ FY2002 } & \multicolumn{3}{|c|}{ FY2002 } & & \multicolumn{2}{|c|}{ FY2003 } & \multicolumn{4}{|c|}{ FY2003 } \\
\hline & Coefficient & S.E. & & Coefficient & S.E. & & Coefficient & S.E. & & Coefficient & S.E. & \\
\hline Care Receiver Characteristics & & & & & & & & & & & & \\
\hline Sex (1=female) & 0.418 & $(0.379)$ & & 0.414 & $(0.380)$ & & 0.807 & $(0.529)$ & c & 0.811 & $(0.529)$ & c \\
\hline Age & 0.041 & $(0.027)$ & c & 0.043 & $(0.026)$ & c & 0.018 & $(0.025)$ & & 0.019 & $(0.025)$ & \\
\hline Dummy for support required & 7.081 & (1.435) & $\mathbf{a}$ & 7.072 & (1.435) & $\mathbf{a}$ & -0.421 & (2.326) & & -0.416 & (2.330) & \\
\hline Dummy for care level 1 & 9.041 & $(0.986)$ & a & 8.989 & $(0.982)$ & $\mathbf{a}$ & 0.508 & $(2.283)$ & & 0.514 & (2.285) & \\
\hline Dummy for care level 2 & 9.347 & $(0.914)$ & a & 9.284 & $(0.914)$ & $\mathbf{a}$ & 1.218 & $(2.331)$ & & 1.222 & $(2.335)$ & \\
\hline Dummy for care level 3 & 8.719 & (1.029) & a & 8.623 & (1.036) & $\mathbf{a}$ & 1.812 & $(2.380)$ & & 1.813 & (2.385) & \\
\hline Dummy for care level 4 & 9.318 & $(0.890)$ & $\mathbf{a}$ & 9.249 & $(0.876)$ & $\mathbf{a}$ & 2.602 & (2.358) & & 2.601 & (2.365) & \\
\hline Dummy for care level 5 & 10.133 & $(0.921)$ & a & 10.051 & $(0.911)$ & $\mathbf{a}$ & 2.272 & $(2.366)$ & & 2.272 & $(2.372)$ & \\
\hline $\begin{array}{l}\text { Dummy for disease that caused care needs : Cardiovascular diseases, e.g., } \\
\text { hypertension and arteriosclerosis }\end{array}$ & -0.588 & $(0.503)$ & & -0.518 & $(0.509)$ & & 0.210 & $(0.440)$ & & 0.213 & $(0.442)$ & \\
\hline $\begin{array}{l}\text { Dummy for disease that caused care needs : Heart-related chronic diseases, e.g., } \\
\text { angina pectoris }\end{array}$ & -1.837 & $(0.899)$ & $\mathbf{a}$ & -1.832 & $(0.904)$ & $\mathbf{a}$ & 0.117 & $(0.501)$ & & 0.121 & $(0.503)$ & \\
\hline Dummy for disease that caused care needs : Diabetes & -0.172 & $(0.587)$ & & -0.172 & $(0.596)$ & & 0.962 & $(0.576)$ & b & 0.954 & $(0.580)$ & $\mathbf{b}$ \\
\hline $\begin{array}{l}\text { Dummy for disease that caused care needs : Brain-related chronic diseases, e.g., } \\
\text { cerebral infarction and subarachnoid hemorrhage }\end{array}$ & 0.607 & $(0.682)$ & & 0.573 & $(0.688)$ & & -1.637 & $(1.310)$ & & -1.637 & (1.314) & \\
\hline $\begin{array}{l}\text { Dummy for disease that caused care needs : Chronic diseases related to digestive } \\
\text { organs, e.g., chronic hepatitis, gastric ulcers, duodenal ulcers }\end{array}$ & -0.472 & $(0.859)$ & & -0.479 & $(0.853)$ & & 0.464 & $(0.581)$ & & 0.461 & $(0.582)$ & \\
\hline $\begin{array}{l}\text { Dummy for disease that caused care needs : Respiratory disease, e.g., asthma and } \\
\text { chronic bronchitis (CB) }\end{array}$ & -0.354 & $(0.459)$ & & -0.337 & $(0.463)$ & & 0.202 & $(0.411)$ & & 0.199 & $(0.410)$ & \\
\hline $\begin{array}{l}\text { Dummy for disease that caused care needs : Low back pain, muscle stiffness of the } \\
\text { shoulder, arthritis, and rheumatism }\end{array}$ & -3.536 & $(1.362)$ & $\mathbf{a}$ & -3.500 & (1.348) & a & 0.122 & $(0.801)$ & & 0.120 & $(0.804)$ & \\
\hline $\begin{array}{l}\text { Dummy for disease that caused care needs : Eye related diseases, e.g., glaucoma } \\
\text { and cataracts }\end{array}$ & -0.003 & $(0.576)$ & & 0.030 & $(0.585)$ & & -0.519 & $(0.721)$ & & -0.516 & $(0.722)$ & \\
\hline $\begin{array}{l}\text { Dummy for disease that caused care needs : Kidney related diseases, e.g., chronic } \\
\text { renal failure }\end{array}$ & 0.054 & $(0.393)$ & & 0.077 & $(0.389)$ & & -0.510 & $(0.464)$ & & -0.507 & $(0.466)$ & \\
\hline $\begin{array}{l}\text { Dummy for disease that caused care needs : Anal diseases, e.g., incarcerated } \\
\text { hemorrhoids and thrombosed external hemorrhoids }\end{array}$ & -0.725 & $(1.262)$ & & -0.662 & (1.275) & & 1.045 & $(0.780)$ & & 1.046 & $(0.785)$ & \\
\hline disease & -0.401 & $(0.463)$ & & -0.378 & $(0.460)$ & & -0.182 & $(0.394)$ & & -0.179 & $(0.397)$ & \\
\hline Dummy for disease that caused care needs : Mental disorders, e.g., depression & 0.045 & $(0.438)$ & & 0.061 & $(0.434)$ & & 0.104 & $(0.349)$ & & 0.099 & $(0.352)$ & \\
\hline Hours of care needed per day & 0.074 & $(0.039)$ & b & 0.075 & $(0.039)$ & b & 0.038 & $(0.032)$ & & 0.038 & $(0.032)$ & \\
\hline
\end{tabular}


Table 3 (continued)

\begin{tabular}{|c|c|c|c|c|c|c|c|c|c|c|c|c|}
\hline \multirow[b]{2}{*}{ Variables } & \multicolumn{2}{|c|}{ FY2002 } & \multicolumn{3}{|c|}{ FY2002 } & & \multicolumn{2}{|c|}{ FY2003 } & \multicolumn{4}{|c|}{ FY2003 } \\
\hline & Coefficient & S.E. & & Coefficien & S.E. & & Coefficient & S.E. & & Coefficient & S.E. & \\
\hline \multicolumn{13}{|l|}{ Use of medical care } \\
\hline Number of outpatient days per month & 0.050 & $(0.051)$ & & 0.051 & $(0.052)$ & & 0.067 & $(0.039)$ & b & 0.067 & $(0.040)$ & b \\
\hline Out-of-pocket medical expenditure per month (natural log) & 0.008 & $(0.055)$ & c & 0.006 & $(0.055)$ & & 0.090 & $(0.052)$ & b & 0.090 & $(0.052)$ & b \\
\hline \multicolumn{13}{|l|}{ Household characteristics } \\
\hline Household income (natural log) & 0.954 & $(0.398)$ & $\mathbf{a}$ & 0.969 & (0.399) & $\mathbf{a}$ & -0.129 & $(0.391)$ & & -0.125 & $(0.397)$ & \\
\hline Household assets (natural log) & 0.354 & $(0.168)$ & a & 0.341 & $(0.169)$ & $\mathbf{a}$ & -0.063 & $(0.173)$ & & -0.063 & $(0.174)$ & \\
\hline $\begin{array}{l}\text { Dummy for households where the household budget is shared between the elderly } \\
\text { person and other household members (yes=1) }\end{array}$ & 0.278 & $(0.422)$ & & 0.287 & $(0.424)$ & & 0.047 & $(0.440)$ & & 0.052 & $(0.438)$ & \\
\hline Share of care receiver's assets in total household assets & 0.643 & $(0.465)$ & & 0.609 & $(0.472)$ & & -0.860 & $(0.449)$ & b & -0.866 & $(0.450)$ & b \\
\hline Number of family members & 0.097 & $(0.129)$ & & 0.107 & $(0.128)$ & & 0.036 & $(0.131)$ & & 0.037 & $(0.132)$ & \\
\hline Tenant status ( $1=$ own house) & -0.391 & $(0.689)$ & & -0.451 & $(0.671)$ & & -0.066 & $(0.453)$ & & -0.071 & $(0.462)$ & \\
\hline \multicolumn{13}{|l|}{ Care Provider Intensity (prefecture level) } \\
\hline Number of establishments per approved persons in the prefecture & 85.589 & (122.026) & & 0.752 & $(193.924)$ & & 297.286 & $(150.820)$ & a & 283.708 & (192.264) & c \\
\hline Share of for-profits & --- & --- & & -2.526 & (3.626) & & --- & --- & & -0.355 & (2.689) & \\
\hline Constant & -27.805 & (7.887) & a & -26.839 & (8.274) & a & 5.743 & (6.348) & & 5.817 & (6.321) & \\
\hline Number of observations & \multirow{2}{*}{\multicolumn{2}{|c|}{$\begin{array}{c}290 \\
0.292\end{array}$}} & \multirow{2}{*}{\multicolumn{4}{|c|}{$\begin{array}{c}290 \\
0.294\end{array}$}} & \multirow{2}{*}{\multicolumn{2}{|c|}{314}} & \multirow{2}{*}{\multicolumn{4}{|c|}{$\begin{array}{c}314 \\
0213\end{array}$}} \\
\hline Adjusted R squared & & & & & & & & & & & & \\
\hline
\end{tabular}

(Notes) All regressions include regional dummies, which were constructed by grouping prefectures into 10 groups. Robust standard errors are used. a b 、 c refer to a significance level of $5 \%, 10 \%$ and $15 \%$, respectively. 
Table 4: Results for the first difference estimation

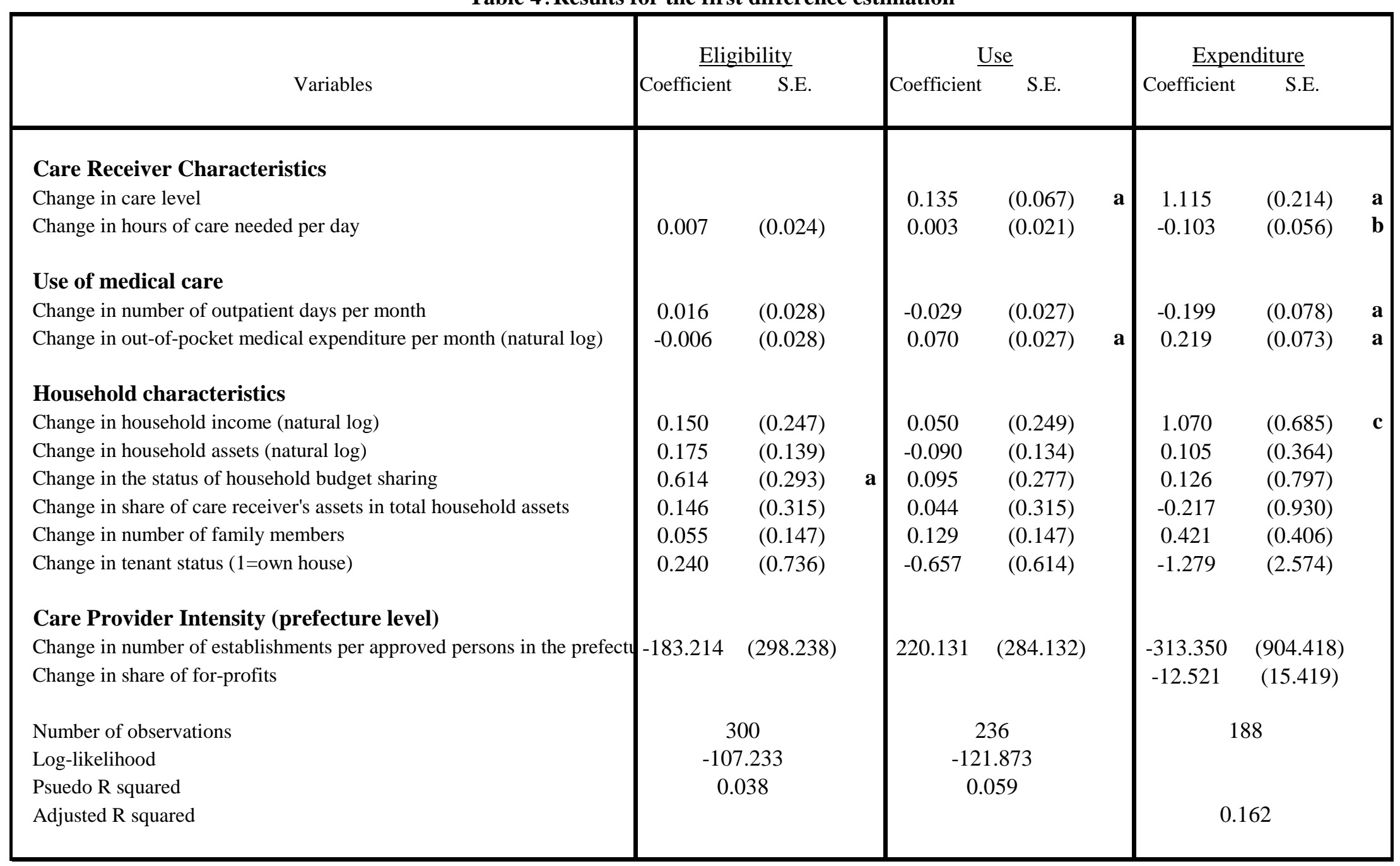

(Notes) a b $、$ c refer to a significance level of $5 \%, 10 \%$ and $15 \%$, respectively. 